\title{
Sports Psychiatric Examination in Competitive Sports
}

\author{
Sportpsychiatrische Untersuchung im Leistungssport
}

ACCEPTED: September 2021

PUBLISHED ONLINE: October 2021

Gonzalez Hofmann C, Wyssen A, Schorb A,

Allroggen M, Dallmann P, Schmidt RE,

Graffius S-T, Niebauer J, Herfert J,

Fröhlich S, Scherr J, Claussen MC. Sports psychiatric examination in competitive sports. Dtsch Z Sportmed. 2021; 72: 307-

315. doi:10.5960/dzsm.2021.502

\section{Summary}

Pre-Participation Examination (PPE) is recommended in many countries prior to or during the practice of competitive sports. The dedicated exploration of psychological complaints and illnesses in the sense of a psychiatric basic assessment within the PPE is not yet the rule.

The implementation of a Psychiatric Basic Assessment (PBA) in the PPE is proposed and presented in terms of content. Abnormal findings in the PBA, crises, emergencies as well as conspicuous changes in behaviour should lead to further sports psychiatric evaluation (SPE) by child, adolescent and adult psychiatrists and psychotherapists qualified for this purpose.

The goal is to use diagnostic and procedural standards to identify risks to mental health, stress, and already manifest illnesses in a timely manner and to provide qualified, specialized medical or psychiatric treatment. The diagnostic standards are intended to promote research and the benefits are to be verified by studies.

\section{KEY WORDS:}

Psychiatric Basic Assessment (PBA), Sports Psychiatric Evaluation (SPE), Mental Health, Mental Disorders, Pre-Participation Examination (PPE)

\section{Zusammenfassung}

Die Sportmedizinische Untersuchung (SMU) wird in vielen Ländern vor bzw. während der Ausübung von Leistungssport empfohlen. Die dezidierte Exploration psychischer Beschwerden und Erkrankungen im Sinne eines psychiatrischen Basis-Assessment innerhalb der SMU ist noch nicht die Regel.

Die Implementierung eines Psychiatrischen BasisAssessments (PBA) in die SMU wird vorgeschlagen und inhaltlich dargestellt. Auffällige Befunde in dem PBA, Krisen, Notfälle sowie auffällige Änderungen des Verhaltens sollten zur weiteren sportpsychiatrischen Evaluation (SPE) durch dafür qualifizierte Kinder-, Jugend- und Erwachsenenpsychiater und -psychotherapeuten führen.

Ziel ist es, anhand diagnostischer und prozeduraler Standards, Risiken für die psychische Gesundheit, Belastungen und bereits manifeste Erkrankungen rechtzeitig zu erkennen und einer qualifizierten, fachärztlichen bzw. fachpsychologischen Behandlung zuzuführen. Die diagnostischen Standards sollen die Forschung begünstigen und der Nutzen durch Studien überprüft werden.

\section{SCHLÜSSELWÖRTER:}

Psychiatrisches Basis-Assessment (PBA),

Sportpsychiatrische Evaluation (SPE), Psychische

Gesundheit, Psychische Erkrankung,

Sportmedizinische Untersuchung (SMU)
Introduction

Mental illness occurs with similar frequency in competitive sports as in the general population (55). Some sports are associated with an increased, sport-specific risk for the development of mental illness. Mental stress and illness increase the risk for injury, and vice versa (55). Therefore, a diagnostic methodology is needed to detect psychiatric complaints as early as possible in competitive athletes. The diagnostics of psychiatric complaints and illnesses is one of the central tasks of medical or psychiatric-psychotherapeutic activities and forms the foundation of medical and psychotherapeutic action $(10,49)$.

While sports medicine can look back on a long tradition and anchoring in competitive sports, sports psychiatry is not yet really established in competitive sports (15). This is reflected on the one hand by the still insufficient sports psychiatric treatment possi- bilities, and on the other hand by the still insufficient evaluation of psychiatric complaints and illnesses in the Pre-Participation Examination (PPE; in Germany SMU; in Switzerland: SPU). Research that promotes a differentiated understanding of mental illness in competitive sport and possible sport-specific phenotypes also needs further development (4). There is a lack of data on the utility of psychiatric assessment within or complementary to PPE.

The requirements for reliable diagnostics in terms of specificity and sensitivity as well as with regard to time and money economy are high; in addition, overdiagnosis must be avoided and the rate of false positive results must be kept low $(13,51)$. Acceptance on the part of the physicians/psychiatrists, performing the test and the athletes concerned must also be taken into account. Sports psychiatrists and >
1. PRACTICE FOR PSYCHIATRY AND PSYCHOTHERAPY, Romanshorn, Switzerland

2. UNIVERSITY BERN, University Hospital of Child-and Adolescence Psychiatry and Psychotherapy, Bern, Switzerland

3. PARACELSUS MEDICAL UNIVERSITY SALZBURG, University Hospital of
Psychiatry, Psychotherapy and Psychiatry, Psychotherapy and
Psychosomatics, Salzburg, Austria

4. UNIVERSITY OF ULM, University Hospital, Clinic for Child-and Adolescence Clinic for Child-and Adolescence
Psychiatry and Psychotherapy, Ulm, Germany

5. UNIVERSITY OF HEIDELBERG, University Hospital Heidelberg, Clinic for General Psychiatry, Heidelberg, Germany

6. UNIVERSITY OF GENEVA, Department of Psychology, Faculty of Psychology and Educational Sciences, Geneva, Switzerland

7. UNIVERSITY OF ZURICH, Department of Psychiatry, Psychotherapy and Psychosomatics, Psychiatric University Hospital Zurich, Zurich, Switzerland

8. PARACELSUS MEDICAL UNIVERSITY SALZBURG, University Institute of Sports Medicine, Prevention and Rehabilitation, and Research Institute of Molecular Sports Medicine and Rehabilitation, Salzburg, Austria

9. ATHLETE PERFORMANCE CENTER, Thalgau, Austria

10. UNIVERSITY OF ZURICH, University Center of Prevention and Sports Medicine, Balgrist University Hospital, Zurich, Switzerland

11. PRIVATE CLINIC WYSS AG, Muenchenbuchsee, Switzerland

12. PSYCHIATRIC SERVICES GRISONS, Adult Psychiatry, Chur, Switzerland

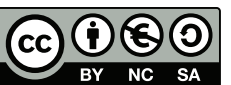

Article incorporates the Creative Commons Attribution - Non Commercial License. https://creativecommons.org/licenses/by-nc-sa/4.0/



\section{CORRESPONDING ADDRESS:}

Dr. med. Carlos Gonzalez Hofmann Practice for Psychiatry and Psychotherapy Friedrichshafnerstraße 55a,

8590 Romanshorn, Switzerland

๑ : c.gonzalez-hofmann@hin.ch 
Content of the national Pre-Participation Examinations and the recommendations of several Sport Associations. DBS=German Para-Sport Association e.V., DGSP=German Society for Sport Medicine and Prevention, FIFA=World Soccer Association, IOC=International Olympic Committee, ÖGSMP=Austrian Society for Sport Medicine and Prevention, SEMS=Sport \& Exercise Medicine Switzerland, TUE=Therapeutic Use Exemption, UEFA=European Soccer Association, USA=Consensus of the US american medical societies. $\mathrm{X}=$ existing, $(\mathrm{x})=$ planned, $\mathrm{X}^{\circ}=$ in „Neurology", $\approx=$ conditional existing

\begin{tabular}{|c|c|c|c|c|c|c|c|c|}
\hline & DGSP & ÖGSMP & SEMS & USA & DBS & $10 \mathrm{C}$ & FIFA & UEFA \\
\hline General life satisfaction & & & $(L-1)$ & & & & & \\
\hline General wellbeing & & & WHO-5 & & & & & \\
\hline Psychiatric pre-diagnosis & $\approx$ & $\approx$ & $\approx$ & $x$ & & & & $\approx$ \\
\hline General mental complaints & $\approx$ & $x$ & $\approx$ & $x$ & & $x^{\circ}$ & & \\
\hline Depression & & & WH0-5 & $x$ & & & & \\
\hline Anxiety & & & WHO-5 & $x$ & & & & \\
\hline Sleep problems & $x$ & & WHO-5 & & & & & $x$ \\
\hline \multicolumn{9}{|l|}{ Concentration } \\
\hline Recreation & $x$ & & $x$ & & & & & \\
\hline Performance & $x$ & $x$ & $x$ & & & & & \\
\hline \multicolumn{9}{|l|}{ Satisfaction with physique } \\
\hline \multicolumn{9}{|l|}{ Social integration } \\
\hline \multicolumn{9}{|c|}{ Experience of harassment, abuse } \\
\hline Pain & & $x$ & $\approx$ & & & & $x$ & $x$ \\
\hline Eating behavior & $\approx$ & & $x$ & $x$ & & $x$ & & $x$ \\
\hline Weight, size & $x$ & $x$ & $x$ & $x$ & $x$ & $x$ & $x$ & $x$ \\
\hline Nicotine & $x$ & $x$ & $x$ & $x$ & & & & \\
\hline Alcohol & $x$ & $x$ & $x$ & $x$ & & & & \\
\hline Drugs & $x$ & & $x$ & $x$ & & & & \\
\hline Doping substances & $x$ & & $x$ & $x$ & & & & \\
\hline Psychosocial risk factors & & & $x$ & $\approx$ & & & & \\
\hline TUE & & & $x$ & & $x$ & $x$ & & $x$ \\
\hline
\end{tabular}

psychotherapists pursue the goal of identifying and adequately treating all athletes in need of assessment and treatment. On the other hand, the motivation of athletes to undergo extensive and time-consuming screening for possible psychiatric complaints and illnesses every year is considered to be rather low. Thus, there is a risk of underdiagnosis.

It is of great importance that mental stress and illnesses in the field of competitive sports receive attention, are adequately included in standard diagnostics, and thus also become less taboo and less stigmatized.

At the same time, however, care must be taken to ensure that neither pathologization nor psychiatrization occurs, for example, non-treatment-relevant competitive anxiety. Therefore, there is a need not only for reliable diagnostic tools, but also for action guidelines and decision heuristics that steer the diagnostic process and support the diagnosis and the subsequent intervention planning.

To date, there are no internationally established, uniform diagnostic standards within sports medicine with regard to mental illnesses. Specific diagnostics, together with a well-founded etiological understanding, is the only way to set the course for goal-oriented therapeutic measures that are intended to promote, maintain and restore the performance and health of athletes. The procedure should be designed age-appropriately so that it can be applied to children, adolescents and adults in competitive sports. The PPE corresponds to such diagnostics. The focus of PPE is on physical complaints, the prevention of serious diseases and injuries, for example sudden cardiac death.
A position paper by leading European professional societies emphasized the predominant benefit of cardiac screening for the diagnosis of cardiac disease in the PPE, provided specific guidance on this, and established criteria for interpretation of findings (50). PPE also serves to assess risk and also has a preventive character (41). In addition to physical complaints, which should ideally be detected and treated at an early stage through regular examinations before health problems or performance impairments develop, psychological stress factors, including diagnosable mental illnesses, are also widespread in competitive sports and can significantly limit performance $(4,67)$.

Athletes are characterized by versatile resources and resilience factors (e.g., high motivation, self-efficacy), but also show an increased risk with regard to the development of some mental illnesses, e.g., due to injuries, failure, and very high demands on physical and mental performance (27). For example, there is a particular risk of developing an eating disorder in the context of weight-sensitive sports (11). Mental health must be differentiated from mental strength (30). Athletes can develop psychiatric complaints and be mentally strong at the same time, which is why mental health complaints can remain undetected. Therefore, the implementation of a diagnostic standard for mental complaints is necessary. This also applies to athletes with physical disabilities, whose special needs must be taken into account (68). 


\section{Current Status of Psychiatric Evaluation within the Pre-Participation Examination (PPE)}

To date, the data collection regarding mental illness has only found its way into the PPE in isolated cases. There are differing views on the necessity of collecting such data. The question arises as to what should be included in psychiatric assessment in the PPE and what scope is accepted by athletes.

While in most countries PPE is not legally regulated and sports federations recommend or require PPE, there are countries where all competitive athletes are legally required to perform PPE $(45,69,72)$. In German-speaking countries, the implementation of PPE is essentially based on voluntariness. In the case of voluntariness, there is a risk that athletes unfit for sport remain undetected and - despite medical contraindication - actively participate in sport (37). Standardized algorithms exist for performing PPE $(37,56)$.

The cost of the examination must usually be borne by the athletes themselves. This can render access to PPE difficult or restrict it, especially in economically weaker countries (20).

Both the national societies for sports medicine and the international sports federations have developed their own standards for the diagnostics of psychiatric complaints within sports medicine diagnostics. Accordingly, the different examination forms and the questions they contain are heterogeneous.

The International Olympic Committee (IOC) points out the purpose of data collection for the purpose of monitoring health problems in sport and developing appropriate prevention measures (3).

Data on the usefulness of PPE as a prevention measure are scarce, and no evaluation of the psychiatric data collected as part of PPE (e.g., pre-existing psychiatric conditions, substance use, mental health complaints) has yet been conducted.

In addition, a standardized algorithm for further sports psychiatric evaluation (SPE) of suspicious findings or reported complaints has not yet been established. The integration of questions on mental health or psychiatric complaints and illnesses may help to identify previously unrecognized complaints in need of treatment at an early stage (1).

Table 1 shows the partly different contents of the PPE on mental health complaints of the German Society for Sports Medicine and Prevention (DGSP), Austrian Society for Sports Medicine and Prevention (ÖGSMP), Sport \& Exercise Medicine Switzerland (SEMS), and the federation of US professional societies as well as the German Disabled Sports Association (DBS), the World Football Association (FIFA), and the European Football Association (UEFA), compared with the IOC recommendations (Table 1) (55).

\section{Figure 1}

\section{Figure 2}



Algorithm about integration of the Psychiatric Basic Assessment (PBA) and the Sport Psychiatric Evaluation (SPE) into Pre-Participation Examination (PBE).

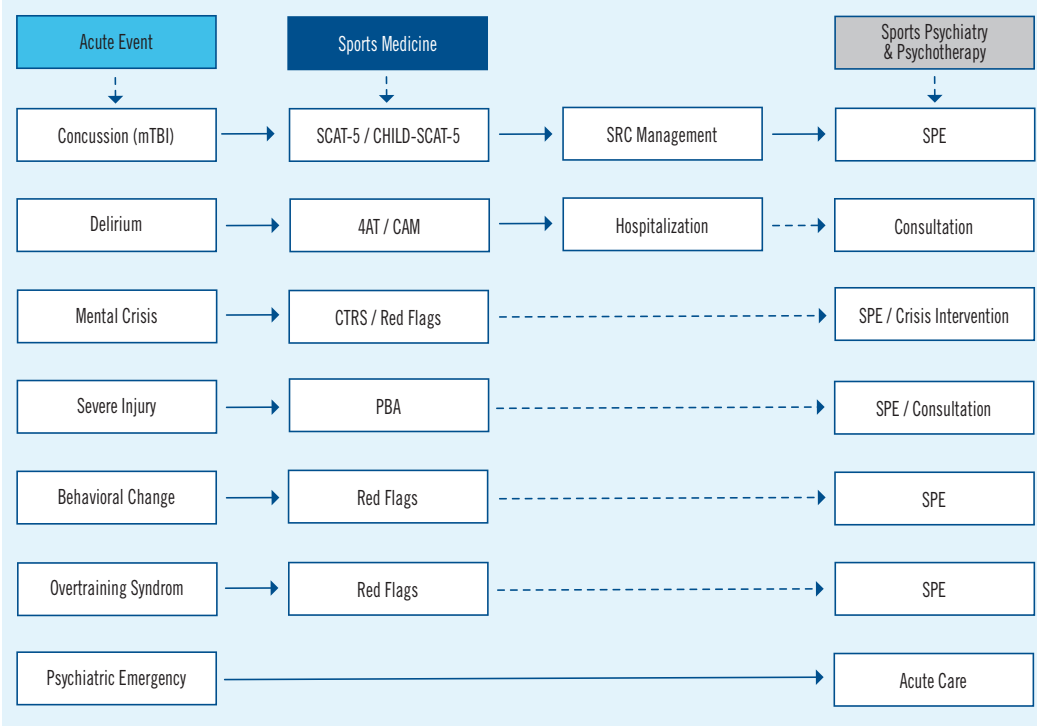

Flow Chart about the implementation of a Sport Psychiatric Evaluation (SPE)

The PPE of the SEMS includes the WHO-5 Well-Being Index (WHO-5) as well as questions on eating behavior, possible psychosocial stress and substance use. This PPE thus proves to be the most comprehensive in terms of recording mental health. In the USA, the Patient Health Questionnaire in its short form with 4 questions (PHQ-4) is part of the PPE $(39,43)$. 
Table 2

Content of the Psychiatric Basic Assessment (PBA).

GENERAL ITEMS

Psychiatric pre-diagnosis

General mental Complaints

Psychosocial risk factors

Social integration

General life satisfaction

Generell well-being

\section{Table 4}

Recommended additional content of the Psychiatric Basic-Assessment (PBA).

\section{COMPLAINT-SPECIFIC} CONTENT

Depressive complaints

Anxiety complaints

Sleep problems

Concentration

Eating behavior

Experience of harassment, abuse
SUBSTANCE ANAMNESIS

Medication incl. supplements

Therapeutic use exemption (TUE)

Nicotine

Alcohol

Drugs

Doping substances

\section{Assessment of Mental Health Complaints and IIInesses in Competitive Sports}

Available assessments of mental health and well-being in competitive sports, actually not included in PPE, include the Baron Depression Screener for Athletes (BDSA) (5) and the Sport Mental Health Assessment Tool 1 (SMHAT-1) (29.) The BDSA is intended as a self-screening tool for athletes, with ten items for typical depressive symptoms. Given a score of $\geq 5$, further evaluation by a psychiatrist and psychotherapist is recommended.

Gouttebarge et al. propose the SMHAT-1 as a screening for psychological complaints to be used by sports physicians or other "licensed health professionals" such as sports psychologists, sports physical therapists, or athletic trainers (29). The SMHAT-1 is designed for athletes 16 years of age and older. The Athlete Psychological Strain Questionnaire (APSQ; 10 items) is used to determine stress exposure. A score $\geq 17$ or higher should be assessed by the aforementioned caregivers to determine whether further clarification is needed. In the next step, six questionnaires will be used for screening:

- General Anxiety Disorder-7 (GAD-7; 7 Items) (66)

Patient Health Questionnaire-9 (PHQ-9; 9 Items) (38)

- Athlete Sleep Screening Questionnaire (ASSQ; 15 Items) (59)

Alcohol Use Disorders Identification Test Consumption (AUDIT-C; 3 Items) (61)

Cutting Down, Annoyance by Criticism, Guilty Feeling, and Eye-openers Adapted to Include Drugs (CAGE-AID; 4 Items) (12) Brief Eating Disorder in Athletes Questionnaire (BEDA-Q; 9 Items) (47)

If all results are negative, a brief intervention (e. g. psychoeducation, mindfulness exercises, mental skills training) and subsequent monitoring should take place.

If at least the result of one questionnaire is positive, a detailed complaint assessment should be performed by sports physicians or clinically trained sports psychologists. If the score is $\geq 1$ on item 9 (life distress thoughts) of the PHQ-9, the athlete's safety should be ensured immediately.
An evaluation using SMHAT-1 runs the risk that highly adapted athletes or those with other complaints are not recorded, especially because no Psychiatric Basis Assessment (PBA) in the narrower sense is integrated. The comprehensive assessment relies solely on self-report questionnaires, with the possibility of false negative results ("underreporting”) (44).

Conducting of medical diagnostics by persons who have neither medical/psychiatric nor clinical-psychological training should be critically questioned. Neither approach (BDSA and SMHAT-1) has been widely used to date.

For the diagnostics of relative energy deficiency in sport (RED-S), the RED-S Specific Screening Tool (RTS) is a questionnaire (males: 25 items, females: 31 items) that differentiates between under-16-year-old and 16-year-old or older athletes (26). Another valid screening tool is the Brief Eating Disorder in Athletes Questionnaire (BEDA-Q) with 9 items (47). The RED-S Clinical Assessment Tool (RED-S CAT) was developed as a clinical instrument (53). Based on clinical features and medical findings, the risk for complications is signaled via the categories "Red," "Yellow," and "Green light," accompanied by a Return to Play (RTP) procedure. This describes a gradual re-entry into sport. In the case of a RED-S requiring treatment, a treatment contract is drawn up.

The aforementioned diagnostics tools or procedures have not yet found widespread application or entry into diagnostic algorithms. In addition, the Profile of Mood States 2nd Edition (POMS) should be mentioned, which is mainly used in sports psychology $(33,48)$. It is relatively comprehensive (adults: 65 items, ages 13-17: 60 items). Two short versions with 35 items each are available. With its five subscales, the POMS primarily measures aspects of mood, which can also reflect depressive and anxious complaints.

\section{Psychiatric Basic Assessment}

Based on the existing situation, the question arises as to how the assessment of mental health complaints within the PPE in the sense of a PBA can look in the future. The question also arises as to when and to what extent this should be followed by an SPE. There are partly different perspectives on these questions among sports psychiatrists as well as among sports physicians. There is usually consensus that the costs and benefits should be weighed against and should be in an adequate relationship to each other. Hitherto no model or guideline exists fort he sctructured and systematic psychiatric diagnostic in competitive sports.

In order to be able to meet the need for early detection and prevention, a standard psychiatric screening as well as further examinations in case of conspicuous results within the framework of the PPE are required.

An appropriate algorithm is required for the implementation of sports psychiatric diagnostics in sports medicine and competitive sports. For this to succeed, results must be unambiguous and the time required must be minimal. Such a model will be presented here. It is based on the annual PPE and includes the PBA as a part of the PPE (Figure 1). As a diagnostic standard in competitive sports, an annual PPE should be mandatory and a PBA should be integrated.

The following parameters should always be included as PBAs in an PPE and elicited (Table 2):

The psychiatric case history (perhaps assessment) should include previous psychiatric diagnoses, current mental health problems and illnesses, as well as psychosocial risk factors and subjective social integration. 
Comparison of Athlete Psychological Strain Questionnaire (APSQ), Patient Health Questionnaire - Short form with 4 Items (PHQ-4) and WH0-5-Wellbeeing-Index (WH0-5)

\begin{tabular}{|c|c|c|c|c|c|c|}
\hline ASSESSMENT & ITEMS & SENSITIVITY & SPECIFITY & CUT-OFF & AGE & EVALUATION OF: \\
\hline APSQ (29) & 10 & $93 \%$ & $79 \%$ & $\geq 17$ Points & $\geq 18$ years & $\begin{array}{l}\text { Performance, } \\
\text { Wellbeing }\end{array}$ \\
\hline PHQ-4 (39) & 4 & $92 \%$ & $78 \%$ & $\geq 6$ Points & $\geq 16$ years & $\begin{array}{l}\text { Anxiety, } \\
\text { Depression }\end{array}$ \\
\hline WНО-5 $(23,70,76)$ & 5 & $93-94 \%$ & $64-78 \%$ & $\begin{array}{c}\leq 12 \text { Points } \\
\leq 50 \%\end{array}$ & $\geq 9$ years & $\begin{array}{l}\text { Wellbeing, Anxiety, } \\
\text { Depression }\end{array}$ \\
\hline
\end{tabular}

\section{Table 5}

Screening-tools of the Sport Psychiatric Evaluation (SPE); ${ }^{*}=$ according to age and sex specific Normwerte, L-1=General wellbeing, RS-13=Resilience Scale - short form 13, SWE=Scala for general self efficiency, WH0-5=WH0-Wellbeing Index.

\begin{tabular}{lcccc}
\multicolumn{1}{r}{ ASSESSMENT } & CUT OFF & ITEMS & SCALES & AGE \\
\hline WH0-5 & $<50$ & 5 Items & 6-Points Likert Scale & $\geq 9$ years \\
\hline L-1 & $\leq 5$ & 1 Item & 11-Points Likert Scale & $\geq 18$ years \\
\hline SWE & $*$ & 10 Items & 4-Points Likert Scale & $\geq 12$ years \\
\hline RS-13 & $\leq 65$ & 13 Items & 7-Points Likert Scale & $\geq 14$ years \\
\hline
\end{tabular}

In addition to the use of medications and supplements, the existence of a therapeutic use exemption should be inquired about, supplemented by assessing substance history, including doping. This should be done with as little effort as possible, e.g. by means of two-choice questions ("yes", "no"), which should be added to the PBA. An appropriate questionnaire is to be developed. The assessment of quality of life, i. e. life satisfaction and well-being, is part of the psychiatric diagnostics (49).

The extent of general life satisfaction can develop or change independently of general well-being. The single item L-1 can be used to assess general life satisfaction (8). The WHO-5 is recommended for screening for depressive and anxiety-related symptoms and associated sleep disorders. The advantage of the WHO- 5 is that it concisely assesses the possible effects of psychological stress and the most frequently occurring mental health symptoms (Table 3). It maps general well-being and its impairment by depressive or anxiety-related complaints at low cost (5 items) and has proven successful in different patient populations $(23,70,76)$.

The ability to concentrate and eating behavior should also be assessed. There are no suitable short scales for this, nor for questions about experiences of violence and abuse. Twochoice questions can also be used here for screening. In the case of experiences of violence, it should be borne in mind that not only possible experiences as a victim are meant, but also those as a witness. Furthermore, perceived performance capacity, recovery, any pain and satisfaction with the physique should be assessed (Table 4). A useful addition can be the definition of so-called "Red Flags", based on Skårderud's "Red \& Yellow Lights” (52).

\section{Sports Psychiatric Evaluation}

The purpose of the SPE is for psychiatrists and psychotherapists to check the mental health complaints depicted in the PPE PBA that may be relevant to treatment but should only occur when there is a reason based on the results of the PBA. The SPE builds on the PBA and addresses mental health problems more comprehensively and in greater depth.
In the case of the sports psychiatric evaluation as an extension of the PPE, it must be made transparent who receives which information. Such binding and standardized regulations could be ratified via the professional societies or the major sports associations. In the case of the SPE, it cannot be automatically assumed that the health insurers are obliged to pay benefits; if a mental disorder requiring treatment is identified, it must be assumed that the costs will be covered.

In acute crisis events - following a sports medicine assessment - SPE may also be indicated; in psychiatric emergencies, it should be performed after acute care (Figure 2).

The collection of the medical history and psychopathological findings form the basis of the SPE. In addition, a mini-ICFAPP and assessment of the level of functioning by the Global Assessment of Functioning (GAF) or the Children's Global Assessment Scale (CGAS) should be performed (42, 49, 64). The Mini-ICF-APP maps the extent of impairment due to mental health problems in 13 life domains. GAF and CGAS are scales that depict the general level of functioning on the basis of the severity of mental health problems and illnesses. In line with the salutogenesis model, self-efficacy should be assessed with the scale for general self-efficacy expectations (SWE) (63) and resilience with the short form of the resilience scale (RS-13) (40) (Table 5). In the case of conspicuous findings, a mini-DIPS is conducted as a structured interview to elicit psychiatric complaints and help assign diagnoses (46).

In the case of conspicuous screening, further and specific diagnostics with validated instruments should be carried out in a complaint-specific manner and, as a matter of principle, not only by means of self-report questionnaires, but also in the form of interviews. The proposed selection of test instruments is intended to facilitate the operationalization of the assessment and comprehensive data evaluation (see Supplemental Material Online, Table 6).

The above-mentioned instruments are not intended to replace the clinical examination and the exploration of complaint, but rather to supplement them in a targeted manner specific to the complaint or diagnosis. They serve as a comprehensive assessment, as a follow-up for quality assurance > 
purposes and, as objectified findings, are also relevant under insurance law vis-à-vis cost bearers.

It should be noted that although most of the procedures are applicable to older adolescents, some of them have not been evaluated for minors. In addition, specific procedures must be used for younger athletes. Laboratory diagnostics (blood count, transaminases, creatinine, urea, TSH, vitamin D, vitamin B12, folic acid, ferritin) should always be available for differential diagnosis. In addition, drug level checks may be useful. In men, e. g. in the case of depressive symptoms, it may also be useful to check free testosterone. If indicated, urine diagnostics (THC, amphetamine, ethyl glucuronide, benzodiazepines, opiates, cocaine, in women also a pregnancy test) can be performed.

Laboratory diagnostics represent a fundamental part of psychiatric diagnostics in order to exclude somatic differential diagnoses. These should be as obligatory as the physical examination and the assessment of the psychopathological findings (Figure 3). Supplementary, equipment aided diagnostics can consist of EEG, lumbar puncture or cerebral imaging (CT, MRI). For all proposed diagnostic methods, the question of cost coverage must be clarified beforehand. In all cases, diagnostics should be selected according to efficacy, appropriateness and cost-effectiveness. Overdiagnosis and the associated stigmatization due to false-positive findings should be avoided.

\section{Conclusions}

It is necessary to further professionalize psychiatric-psychotherapeutic care in competitive sports (15). This includes the development of uniform quality standards in the diagnostics of mental health problems and illnesses, including the development of suitable screening instruments. This applies in particular to the question of up to what point mental health problems can still be treated without psychiatrists or clinical psychologists, or at what point the involvement of qualified experts should be required. In this context, the definition of so-called "red flags" can be helpful, such as the "red and yellow lights" for RED-S (52). The integration of psychiatric screening as part of PPE is not yet widespread but is considered useful. Aspects such as time economy and acceptance as well as cost coverage must be considered.

The (sports-) psychiatric assessment should be performed using a standardized algorithm. The proposed procedure can be operationalized and the benefit can be verified by studies. From a scientific perspective, the implementation of standard diagnostics for the assessment of mental stress and illnesses within the framework of PPE makes sense, since pooled data sets enable greater meaningfulness. The organizational and financial effort must be in reasonable proportion to the benefit. In particular, the aim should be to achieve the lowest possible rate of false-positive findings and to avoid stigmatizing athletes.

\section{Conflict of Interest}

The authors have no conflict of interest.

\section{Contribution Statement}

CGH and MCC proposed the idea of the paper in discussion with JS. CGH wrote the original draft and developed the concept and model in discussion and together with MCC and JS. All authors reviewed and edited the manuscript. The translation of the German version of the Manuscript was conducted by Ian Needham.
(1) ADAMI PE, SQUEO MR, QUATTRINI FM, DI PAOLO FM, PISICCHIO C, DI GIACINTO B, LEMME E, MAESTRINI V, PELLICCIA A. Pre-Participation Health Evaluation in Adolescent Athletes Competing at Youth Olympic Games: Proposal for a Tailored Protocol. Br J Sports Med. 2019; 53: 1111-1116. doi:10.1136/bjsports-2018-09965

(2) ADLER LA, KESSLER RC, SPENCER T. Adult Adhd Self-Report Scale-V1.1 (Asrs-V1.1). Symptom Checklist, World Health Organization, New York, 2003.

(3) BAHR R, CLARSEN B, DERMAN W, DVORAK J, EMERY CA, FINCH CF, HÄGGLUND M, JUNGE A, KEMP S, KHAN KM, MARSHALL SW, MEEUWISSE W, MOUNTJOY M, ORCHARD JW, PLUIM B, QUARRIE KL, REIDER B, SCHWELLNUS M, SOLIGARD T, STOKES KA, TIMPKA T, VERHAGEN E, BINDRA A, BUDGETT R, ENGEBRETSEN L, ERDENER U, CHAMARI K. International Olympic Committee Consensus Statement: Methods for Recording and Reporting of Epidemiological Data on Injury and Illness in Sport 2020 (Including Strobe Extension for Sport Injury and Illness Surveillance (Strobe-Siis)). Br J Sports Med. 2020; 54: 372-389. doi:10.1136/bjsports-2019-101969

(4) BÄR KJ, MARKSER VZ. Sport Specificity of Mental Disorders: The Issue of Sport Psychiatry. Eur Arch Psychiatry Clin Neurosci. 2013; 263: 205-210. doi:10.1007/s00406-013-0458-4

(5) BARON DA, BARON SH, TOMPKINS J, POLAT A. Assessing and Treating Depression in Athletes. In: Baron Da, Reardon C, Baron Sh, Et Al, Eds. Clinical Sports Psychiatry: An International Perspective. Chichester. West Sussex: Wiley, 2013, 65-78.

(6) BARON-COHEN S, WHEELWRIGHT S, ROBINSON J, WOODBURY-SMITH M. The Adult Asperger Assessment (AAA): A Diagnostic Method. J Autism Dev Disord. 2005; 35: 807-819. doi:10.1007/s10803-0050026-5
(7) BEIERLEIN C, KOVALEVA A, KEMPER CJ, RAMMSTEDT B. Kurzskala zur Erfassung der Risikobereitschaft (R-1). Zusammenstellung Sozialwissenschaftlicher Items und Skalen (Zis). 2015. doi:10.6102/zis236

(8) BEIERLEIN C, KOVALEVA A, LÁSZLó Z, KEMPER CJ, RAMMSTEDT B. Kurzskala zur Erfassung der allgemeinen Lebenszufriedenheit (L-1). Zusammenstellung Sozialwissenschaftlicher Items und Skalen (ZIS). 2015. doi:10.6102/zis229 [25th March 2021].

(9) BELLELLI G, MORANDI A, DAVIS DH, MAZZOLA P, TURCO R, GENTILE S, RYAN T, CASH H, GUERINI F, TORPILLIESI T, DEL SANTO F, TRABUCCHI M, ANNONI G, MACLULLICH AMJ. Validation of the 4at, a New Instrument for Rapid Delirium Screening: A Study in 234 Hospitalised Older People. Age Ageing. 2014; 43: 496-502. doi:10.1093/ageing/afu021

(10) BHUGRA D, VENTRIGLIO A, KUZMAN MR, IKKOS G, HERMANS MH, FALKAI P, FIORILLO A, MUSALEK M, HOSCHL C, DALES J, BEEZHOLD J, RÖSSLER W, RACETOVIC G, GAEBEL W. EPA Guidance on the Role and Responsibilities of Psychiatrists. Eur Psychiatry. 2015; 30: 417422. doi:10.1016/j.eurpsy.2015.02.002

(11) BRATLAND-SANDA S, SUNDGOT-BORGEN J. Eating Disorders in Athletes: Overview of Prevalence, Risk Factors and Recommendations for Prevention and Treatment. Eur J Sport Sci. 2013; 13: 499-508. doi:10.1080/17461391.2012.740504

(12) BROWN RL, ROUNDS LA. Conjoint Screening Questionnaires for Alcohol and Drug Abuse. Wis Med J. 1995; 94: 135-140.

(13) BRUKNER P, WHITE S, SHAWDON A, HOLZER K. Screening of Athletes: Australian Experience'. Clin J Sport Med. 2004; 14: 169-177. doi:10.1097/00042752-200405000-00010 


\section{(14) BUYSSE DJ, REYNOLDS CF III, MONK TH, BERMAN SR, KUPFER DJ.} The Pittsburgh Sleep Quality Index: A New Instrument for Psychiatric Practice and Research. Psychiatry Res. 1989; 28: 193213. doi:10.1016/0165-1781(89)90047-4

(15) CLAUSSEN MC, GONZALEZ HOFMANN C, SCHNEEBERGER AR, SEIFRITZ E, SCHORB A, ALLROGGEN M, FREYER T, HELMIG F, NIEBAUER J, HEFERT J, KLOSTERMEIER E, FRÖHLICH S, SCHERR J. Position paper: Sports psychiatric care provision in competitive sports. Dtsch Z Sportmed. 2021; 72: 313-315. doi:10.5960/dzsm.2021.503

(16) CLOITRE M, SHEVLIN M, BREWIN CR, BISSON JI, ROBERTS NP, MAERCKER A, KARATZIAS T, HYLAND P. The International Trauma Questionnaire: Development of a Self-Report Measure of ICD-11 PTSD and Complex PTSD. Acta Psychiatr Scand. 2018; 138: 536546. doi:10.1111/acps.12956

(17) CONNERS CK, SITARENIOS G, PARKER JDA, EPSTEIN JN. The Revised Conners' Parent Rating Scale (Cprs-R): Factor Structure, Reliability, and Criterion Validity. J Abnorm Child Psychol. 1998; 26: 257-268. doi:10.1023/A: 1022602400621

(18) CONNERS CK, SITARENIOS G, PARKER JDA, EPSTEIN JN. Revision and Restandardization of the Conners Teacher Rating Scale (CTRS-R): Factor Structure, Reliability, and Criterion Validity. J Abnorm Child Psychol. 1998; 26: 279-291. doi:10.1023/A: 1022606501530

(19) CRÖNLEIN T, LANGGUTH B, POPP R, LUKESCH H, PIEH C, HAJAK G, GEISLER P. Regensburg Insomnia Rating Scale (RIS): A New Short Rating Scale for the Assessment of Psychological Symptoms and Sleep in Insomnia; Study Design: Development and Validation of a New Short Self-Rating Scale in a Sample of 218 Patients Suffering from Insomnia and 94 Healthy Controls. Health Qual Life Outcomes. 2013; 11: 65. doi:10.1186/1477-7525-11-65

(20) DAHLSTRÖM Ö, ADAMI PE, FAGHER K, JACOBSSON J, BARGORIA V, GAUFFIN H, HANSSON PO, ANDERSSON C, BERMON S, TIMPKA T. Efficacy of PreParticipation Cardiac Evaluation Recommendations among Athletes Participating in World Athletics Championships. Eur J Prev Cardiol. 2020; 27: 1480-1490. doi:10.1177/2047487319884385

\section{(21) DILLMANN U, NILGES P, SAILE H, GERBERSHAGEN HU. PDI Pain} Disability Index - Deutsche Fassung [Verfahrensdokumentation Aus Psyndex Tests-Nr. 9003694 Und Fragebogen]. In LeibnizZentrum für Psychologische Information und Dokumentation (ZPID) (Hrsg.), Elektronisches Testarchiv. Trier: ZPID, 2011. doi:10.23668/psycharchives.324 [25th March 2021].

(22) DÖPFNER M, GÖRTZ-DORTEN A. Diagnostik-System für Psychische Störungen nach ICD-10 und DSM-5 für Kinder und Jugendliche III. Hogrefe, Göttingen, 2017.

(23) DOWNS A, BOUCHER LA, CAMPBELL DG, POLYAKOV A. Using the WHO5 Well-Being Index to Identify College Students at Risk for Mental Health Problems. J Coll Student Dev. 2017; 58: 113-117. doi:10.1353/csd.2017.0008

\section{(24) FIRST MB, WILLIAMS JBW, SMITH BENJAMIN L, SPITZER RL.} Strukturiertes Klinisches Interview Für DSM- $5^{\circ}-$ Persönlichkeitsstörungen Deutsche Bearbeitung des Structured Clinical Interview for DSM- $5^{\circ}$ - Personality Disorders, Hogrefe, Göttingen.

(25) FOA EB, HUPPERT JD, LEIBERG S, LANGNER R, KICHIC R, HAJCAK G, SALKOVISKIS PM. Obsessive-Compulsive Inventory-Revised, Hogrefe: Göttingen, 2009.

(26) FOLEY DAVELAAR CM, OSTROM M, SCHULZ J, TRANE K, WOLKIN A, GRANGER J. Validation of an Age-Appropriate Screening Tool for Female Athlete Triad and Relative Energy Deficiency in Sport in Young Athletes. Cureus. 2020; 12: e8579-e79. doi:10.7759/ cureus.8579

(27) GALLI N, GONZALEZ SP. Psychological Resilience in Sport: A Review of the Literature and Implications for Research and Practice. Int J Sport Exerc Psychol. 2015; 13: 243-257. doi:10.1080/161219 7X.2014.946947

(28) GILLBERG C, GILLBERG C, RÅSTAM M, WENTZ E. The Asperger Syndrome (and High-Functioning Autism) Diagnostic Interview (ASDI): A Preliminary Study of a New Structured Clinical Interview. Autism. 2001; 5: 57-66. doi:10.1177/1362361301005001006
(29) GOUTTEBARGE V, BINDRA A, BLAUWET C, CAMPRIANI N, CURRIE A, ENGEBRETSEN L, HAINLINE B, KROSHUS E, MCDUFF D, MOUNTJOY M, PURCELL R, PUTUKIAN M, REARDON CL, RICE SM, BUDGETT R. International Olympic Committee (IOC) Sport Mental Health Assessment Tool 1 (SMHAT-1) and Sport Mental Health Recognition Tool 1 (SMHRT-1): Towards Better Support of Athletes' Mental Health. Br J Sports Med. 2021; 55: 30-37. doi:10.1136/bjsports-2020-102411

(30) GUCCIARDI DF, HANTON S, FLEMING S. Are Mental Toughness and Mental Health Contradictory Concepts in Elite Sport? A Narrative Review of Theory and Evidence. J Sci Med Sport. 2017; 20:307-311. doi:10.1016/j.jsams.2016.08.006

(31) HAMILTON M. A Rating Scale for Depression. J Neurol Neurosurg Psychiatry. 1960; 23: 56-62. doi:10.1136/jnnp.23.1.56

(32) HAYES MHS, PATTERSON DG. Experimental Development of the Graphic Rating Method. Psychol Bull. 1921; 18: 98-99.

(33) HEUCHERT JP, MCNAIR DM. Profile of Mood States 2nd Edition, Multi-Health Systems Inc. Toronto, 2012.

(34) HILBERT A, TUSCHEN-CAFFIER B, KARWAUTZ A, NIEDERHOFER H, MUNSCH S. Eating Disorder Examination-Questionnaire. Diagnostica. 2007; 53: 144-154. doi:10.1026/0012-1924.53.3.144

(35) HILBERT A. Eating Disorder Examination-Questionnaire für Kinder. Tübingen: DGVT Verlag, 2016.

(36) JENSEN MP, MCFARLAND CA. Increasing the Reliability and Validity of Pain Intensity Measurement in Chronic Pain Patients. Pain. 1993; 55: 195-203. doi:10.1016/0304-3959(93)90148-I

(37) KENNEDY M, COMER F, YOUNG JA, VALASEK AE. Increasing Primary Care Follow-up after Preparticipation Physical Evaluations. Pediatr Qual Saf. 2020; 5: e358. doi:10.1097/ pq 9.0000000000000358

(38) KROENKE K, SPITZER RL, WILLIAMS JB. The PHQ-9: Validity of a Brief Depression Severity Measure. J Gen Intern Med. 2001; 16: 606613. doi:10.1046/j.1525-1497.2001.016009606.x

(39) KROENKE K, SPITZER RL, WILLIAMS JB, LÖWE B. An Ultra-Brief Screening Scale for Anxiety and Depression: The PHQ-4. Psychosomatics. 2009; 50: 613-621.

(40) LEPPERT K, KOCH B, BRÄHLER E, STRAUSS B. Die Resilienzskala (RS)Überprüfung der Langform RS-25 und einer Kurzform RS-13. Klin Diagn Eval. 2008; 1: 226-243.

(41) LEVY D, DELANEY JSA. Risk/Tolerance Approach to the Preparticipation Examination. Clin J Sport Med. 2012; 22: 309310. doi:10.1097/JSM.0b013e318257d799

(42) LINDEN M, BARON S, MUSCHALLA B. Mini-ICF-Rating für Aktivitätsund Partizipationsbeeinträchtigungen bei Psychischen Erkrankungen. Kurzinstrument zur Fremdbeurteilung von Aktivitäts- und Partizipationsstörungen bei psychischen Erkrankungen in Anlehnung an die Internationale Klassifikation der Funktionsfähigkeit, Behinderung und Gesundheit (ICF) der Weltgesundheitsorganisation, Hogrefe: Göttingen, 2009.

(43) LÖWE B, WAHL I, ROSE M, SPITZER C, GLAESMER H, WINGENFELD K, SCHNEIDER A, BRÄHLER E. 4-Item Measure of Depression and Anxiety: Validation and Standardization of the Patient Health Questionnaire-4 (PHQ-4) in the General Population. J Affect Disord. 2010; 122: 86-95. doi:10.1016/j.jad.2009.06.019

(44) LUDERER M, KAPLAN-WICKEL N, RICHTER A, REINHARD I, KIEFER F, WEBER T. Screening for Adult Attention-Deficit/Hyperactivity Disorder in Alcohol Dependent Patients: Underreporting of ADHD Symptoms in Self-Report Scales. Drug Alcohol Depend. 2019; 195: 52-58. doi:10.1016/j.drugalcdep.2018.11.020

(45) MANN G, DUBNOV-RAZ G, GOLAN R, TSUR A. [the Importance and Composition of Pre-Season Examination in Sportsmen]. Harefuah. 2013; 152: 190-249.

(46) MARGRAF J, CWIK JC. Mini-Dips Open Access: Diagnostic ShortInterview for Mental Disorders. [Mini-Dips Open Access: Diagnostisches Kurzinterview bei Psychischen Störungen]. Bochum: Forschungs- Und Behandlungszentrum für psychische Gesundheit, Ruhr-Universität. Doi:10.13154/Rub.102.91', 2017 
(47) MARTINSEN M, HOLME I, PENSGAARD AM, TORSTVEIT MK, SUNDGOTBORGEN J. The Development of the Brief Eating Disorder in Athletes Questionnaire. Med Sci Sports Exerc. 2014; 46: 16661675. doi:10.1249/MSS.0000000000000276

(48) MCNAIR D, LORR M, DROPPLEMAN L. Manual for the Profile of Mood States. San Diego, Ca: Educational and Industrial Testing Service, 1971.

(49) MEZZICH JE. The WPA International Guidelines for Diagnostic Assessment. World Psychiatry. 2002; 1: 36-39.

(50) MONT L, PELLICCIA A, SHARMA S, BIFFI A, BORJESSON M, BRUGADA TERRADELLAS J, CARRÉ F, GUASCH E, HEIDBUCHEL H, LA GERCHE A, LAMPERT R, MCKENNA W, PAPADAKIS M, PRIORI SG, SCANAVACCA M, THOMPSON P, STICHERLING C, VISKIN S, WILSON M, CORRADO D. Pre-Participation Cardiovascular Evaluation for Athletic Participants to Prevent Sudden Death: Position Paper from the EHRA and the EACPR, Branches of the ESC. Endorsed by APHRS, HRS, and SOLAECE. Eur J Prev Cardiol. 2017; 24: 41-69. doi:10.1177/2047487316676042

(51) MOSTERD A. Pre-Participation Screening of Asymptomatic Athletes : "Don't Do Stupid Stuff”'. Neth Heart J. 2018; 26: 123-126. doi:10.1007/s12471-018-1075-7

(52) MOUNTJOY M, SUNDGOT-BORGEN J, BURKE L, CARTER S, CONSTANTINI N, LEBRUN C, MEYER N, SHERMAN R, STEFFEN K, BUDGETT R, LJUNGQVIST A. The IOC Consensus Statement: Beyond the Female Athlete Triad-Relative Energy Deficiency in Sport (RED-S). Br J Sports Med. 2014; 48: 491-497. doi:10.1136/bjsports-2014-093502

(53) MOUNTJOY M, SUNDGOT-BORGEN J, BURKE L, CARTER S, CONSTANTINI N, LEBRUN C, MEYER N, SHERMAN R, STEFFEN K, BUDGETT R, LJUNGQVIST A, ACKERMAN K. The Ioc Relative Energy Deficiency in Sport Clinical Assessment Tool (RED-S CAT). Br J Sports Med. 2015; 49: 1354. doi:10.1136/bjsports-2015-094873

(54) OSWALD WD. Zahlen-Verbindungs-Test, 3. überarbeitete und neu normierte Auflage, Hogrefe, Göttingen, 2016.

(55) REARDON CL, HAINLINE B, ARON CM, BARON D, BAUM AL, BINDRA A, BUDGETT R, CAMPRIANI N, CASTALDELLI-MAIA JM, CURRIE A, DEREVENSKY JL, GLICK ID, GORCZYNSKI P, GOUTTEBARGE V, GRANDNER MA, HAN DH, MCDUFF D, MOUNTJOY M, POLAT A, PURCELL R, PUTUKIAN M, RICE S, SILLS A, STULL T, SWARTZ L, ZHU LJ, ENGEBRETSEN L. Mental Health in Elite Athletes: International Olympic Committee Consensus Statement (2019). Br J Sports Med. 2019; 53: 667-699. doi:10.1136/bjsports-2019-100715

(56) RIEBE D, FRANKLIN BA, THOMPSON PD, GARBER CE, WHITFIELD GP, MAGAL M, PESCATELLO LS. Updating ACSM's Recommendations for Exercise Preparticipation Health Screening. Med Sci Sports Exerc. 2015; 47: 2473-2479. doi:10.1249/MSS.0000000000000664

(57) RÖSLER M, RETZ-JUNGINGER P, RETZ W, STIEGLITZ R. HASE -Homburger ADHS-Skalen für Erwachsene. Hogrefe, Göttingen, 2008.

(58) SACHSER C, BERLINER L, HOLT T, JENSEN TK, JUNGBLUTH N, RISCH E, ROSNER R, GOLDBECK L. International Development and Psychometric Properties of the Child and Adolescent Trauma Screen (CATS). J Affect Disord. 2017; 210: 189-195. doi:10.1016/j. jad.2016.12.040

(59) SAMUELS C, JAMES L, LAWSON D, MEEUWISSE W. The Athlete Sleep Screening Questionnaire: A New Tool for Assessing and Managing Sleep in Elite Athletes. Br J Sports Med. 2016; 50: 418422. doi:10.1136/bjsports-2014-094332

(60) SATOW L. B5T - Psychomeda Big-Five-Persönlichkeitstest [Fragebogen mit Instruktion]. In Leibniz-Zentrum für Psychologische Information und Dokumentation (ZPID) (Hrsg.) Elektronisches Testarchiv (Psyndex Tests-Nr. 9006357). 2011, Trier: ZPID. doi:10.23668/Psycharchives.410 [25th March 2021].

(61) SAUNDERS IB, AASLAND OG, BABOR TF, DE LA FUENTE JR, GRANT M. Development of the Alcohol Usedisorders Identification Test (AUDIT): WHO Collaborative Project on Early Detection of Persons with Harmful Alcohol Consumption II. Addiction. 1993; 88: 791-804. doi:10.1111/j.1360-0443.1993.tb02093.x
(62) SCHAUB D, JUCKEL G. PSP-Skala - Deutsche Version der Personal and Social Performance Scale: Validiertes Messinstrument zur Erfassung des psychosozialen Funktionsniveaus in der Schizophrenietherapie. Nervenarzt. 2011; 82: 1178-1184. doi:10.1007/s00115-010-3204-4

(63) SCHWARZER R, JERUSALEM M. SWE. Skala zur allgemeinen Selbstwirksamkeitserwartung [Verfahrensdokumentation, Autorenbeschreibung und Fragebogen]. In Leibniz-Institut für Psychologie (ZPID) (Hrsg.), Open Test Archive. 2003, Trier: ZPID. doi:10.23668/Psycharchives.4515 [25th March 2021].

(64) SHAFFER D, GOULD MS, BRASIC J, AMBROSINI P, FISHER P, BIRD H, ALUWAHLIA S. A Children's Global Assessment Scale (CGAS) Arch Gen Psychiatry. 1983; 40: 1228-1231. doi:10.1001/ archpsyc.1983.01790100074010

(65) SIEGRIST P, MAERCKER A. Deutsche Fassung der Short Screening Scale for DSM-IV Posttraumatic Stress Disorder. Trauma Gewalt. 2010; 3: 208-213.

(66) SPITZER RL, KROENKE K, WILLIAMS JBW, LÖWE B. A Brief Measure for Assessing Generalized Anxiety Disorder: The GAD-7. Arch Intern Med. 2006; 166: 1092-1097. doi:10.1001/archinte.166.10.1092

(67) STRÖHLE A. Sports Psychiatry: Mental Health and Mental Disorders in Athletes and Exercise Treatment of Mental Disorders. Eur Arch Psychiatry Clin Neurosci. 2019; 269: 485-498. doi:10.1007/s00406-018-0891-5

(68) SWARTZ L, HUNT X, BANTJES J, HAINLINE B, REARDON CL. Mental Health Symptoms and Disorders in Paralympic Athletes: A Narrative Review. Br J Sports Med. 2019; 53: 737. doi:10.1136/ bjsports-2019-100731

(69) TODOROVSKA L, DEJANOVA B, IVANOVSKA VM. Periodical PreParticipation Physical Examination of Athletes in R. of Macedonia Compared with Other European Countries, Research in Physical Education. Sports Health. 2016; 5: 111-115.

(70) TOPP CW, ØSTERGAARD SD, S $\emptyset$ NDERGAARD S, BECH P. The WHO5 Well-Being Index: A Systematic Review of the Literature. Psychother Psychosom. 2015; 84: 167-176. doi:10.1159/000376585

(71) TURNER PM, TURNER TJ. Validation of the Crisis Triage Rating Scale for Psychiatric Emergencies. Can J Psychiatry. 1991; 36: 651-654. doi:10.1177/070674379103600905

(72) VESSELLA T, ZORZI A, MERLO L, PEGORARO C, GIORGIANO F, TREVISANATO M, VIEL M, FORMENTINI P, CORRADO D, SARTO P. The Italian Preparticipation Evaluation Programme: Diagnostic Yield, Rate of Disqualification and Cost Analysis. Br J Sports Med. 2020; 54: 231-237. doi:10.1136/bjsports-2018-100293

(73) VON KORFF M, DEBAR LL, KREBS EE, KERNS RD, DEYO RA, KEEFE FJ. Graded Chronic Pain Scale Revised: Mild, Bothersome, and High-Impact Chronic Pain. Pain. 2020; 161: 651-661. doi:10.1097/j . pain. 0000000000001758

(74) WALDORF M, CORDES M, VOCKS S, MCCREARY D. Die deutschsprachige Drive for Muscularity Scale (DMS). Zusammenstellung Sozialwissenschaftlicher Items und Skalen (ZIS). 2016. doi:10.6102/zis246 [25th March 2021].

(75) WORLD HEALTH ORGANIZATION (WHO). AUDIT: The Alcohol Use Disorders Identification Test: Guidelines for Use in Primary Health Care / Babor TF, Higgins-Biddle JC, Saunders JB, Monteiro MG, 2nd Ed. World Health Organization. 2001 https: // apps.who.int/iris/handle/10665/67205 [25th March 2021].

(76) WU SFV. Rapid Screening of Psychological Well-Being of Patients with Chronic Illness: Reliability and Validity Test on WHO5 and PHQ-9 Scales. Depress Res Treat. 2014; 2014: 239490. doi:10.1155/2014/239490 